\title{
Wrinkly skin syndrome
}

INSERM

\section{Source}

INSERM. (1999). Orphanet: an online rare disease and orphan drug data base. Wrinkly skin syndrome. ORPHA:2834

Wrinkly skin syndrome (WSS) is characterized by wrinkling of the skin of the dorsum of the hands and feet, an increased number of palmar and plantar creases, wrinkled abdominal skin, multiple skeletal abnormalities (joint laxity and congenital hip dislocation), late closing of the anterior fontanel, microcephaly, pre- and postnatal growth retardation, developmental delay and facial dysmorphism (a broad nasal bridge, downslanting palpebral fissures and hypertelorism). 